\title{
Seroprevalence of cytomegalovirus among healthy students at Diyala University, Diyala, Iraq
}

\author{
Mohammed Khaleefah Khudir and Abdul-Lateef Molan* \\ Department of Biology, College of Sciences, Diyala University, Diyala, Iraq
}

\begin{abstract}
Globally, cytomegalovirus (CMV) is an extremely common viral infection and is one of the most common causes of congenital infections. Although infection with CMV in immunocompetent individuals is selflimiting, infection in immunocompromised individuals is associated with high morbidity and mortality. Consequently, CMV establishes a latent lifetime infection that may be reactivated by changed immune status. Despite its high prevalence, the epidemiology of CMV in the general population is incompletely understood. The purpose of the present study was to assess the CMV seroprevalence in a group of male and female students at Diyala University, Diyala, Iraq during 2012. The impact of residency on the CMV seropositivity was also evaluated. In this study, 186 male and female students at Diayal University were screened for CMV IgG and IgM by enzyme-linked immunosorbent assay (ELISA). A total of 181 (97.4\%) of students were seropositive for CMV IgG. Of those, 95 (51.2\%) were male students and 86 (46.2\%) were female students. In addition, 3 (2 females and 1 male) students (1.6\%) were CMV IgM seropositive. The results showed that the CMV IgG seropositivity rate among students living in rural areas was significantly $(P<0.0001)$ higher than that in those living in the urban areas and that the seropositivity rates with both $\operatorname{Ig} G$ and $\operatorname{IgM}$ were higher in male than in female students. In conclusion, the high seroprevalence of CMV in our group of students indicates the virus is very common in the community, especially in the rural areas of Diyala Province and that the students harbour the virus in their blood which can be potentially infectious when they donate blood.
\end{abstract}

Keywords: cytomegalovirus, seroprevalence, university students, Diyala Province, Iraq

\section{Introduction}

The cytomegalovirus (CMV) belongs to the family Herpesviridae and the members of this family share the ability to remain latent in different cells of the human body for a long time [1]. Globally, CMV is an extremely common viral infection and is one of the most common causes of congenital infections. Some studies have presented some evidences that CMV infection leads to miscarriage and stillbirth [2,3]. Even in infants who are asymptomatic at birth, hearing deficits and ocular damage may appear later and continue to progress during the first few years of life [4]. Recently, Bagheri et al. [5] collected 240 serum samples from pregnant Iranian women and measured the CMV IgG and IgM markers and found that the CMV seroprevalence rate was $72.1 \%$.

Many epidemiological studies have shown an association between CMV seropositivity and atherosclerosis [6, 7]. Froberg et al. [8] determined CMV seropositivity in a group of patients under $50 \mathrm{yr}$ old, in whom serum total cholesterol levels were known in order to determine if CMV seropositivity is associated with higher levels of serum total cholesterol in younger patients. The study provided evidence that CMVseropositivity is associated with higher serum total cholesterol levels in female patients under $50 \mathrm{yr}$ of age, but not in male patients of comparable age.

Although infection with CMV in immunocompetent individuals is self-limiting, infection in immunocompromised individuals is associated with high morbidity and mortality. Consequently, CMV establishes a latent lifetime infection that may be reactivated by changed immune status $[9,10]$.

Despite its high prevalence, the epidemiology of CMV in the general population is incompletely understood. As far as we know, no data are available concerning the seroprevalence of this virus in Diyala Province, Iraq. Accordingly, the present study was to undertaken to assess the seroprevalence of CMV among Diyala University (Middle of Iraq) male and female students during 2012.

\subsection{Study population and setting}

II. Materials and Methods

A total of 186 male and female university students were enrolled for this study. All enrolled students were apparently healthy and medically fit. Demographic information such as age, marital status, and residency were obtained from the participants. Informed consent was also obtained from all participants. The blood samples were collected and the serum samples were separated and stored at $-20{ }^{\circ} \mathrm{C}$ until being used in the assay.

All the sera samples were tested by commercially available Diagnostic CMV IgG ELISA kit (MicroBix BioSystem, Cambridge, UK) and according to the manufacturer's protocol and as described by Froberg et al. [8]. Briefly, the serum samples were incubated in microwells coated with CMV antigen $\left(20 \mathrm{~min}, 25^{\circ} \mathrm{C}\right)$, washed 
to remove unbound antibody and serum components, incubated with peroxidase-conjugated goat anti-human $\operatorname{IgG}\left(20 \mathrm{~min}, 25^{\circ} \mathrm{C}\right)$, washed to remove unreacted conjugate, and incubated with $3,3^{\prime} 5,5^{\prime}$-tetramethylbenzidine $\left(10-12 \mathrm{~min}, 25^{\circ} \mathrm{C}\right)$. The color reaction was terminated by addition of "stop solution" and color intensity was read at $450 \mathrm{~nm}$, using a microplate reader (Molecular Devices, Inc., Sunnyvale, CA). The optical density (OD) of the solution in each microwell was measured against the reagent blank.

Positive high, low, and negative serum controls were included on each microplate and were used to establish the mean OD of the low positive control; this value was used with the manufacturer's correction factor to compute an OD ratio (the OD of each sample divided by the mean OD of the low positive control). Samples with OD ratios $\geq 1.10$ were classified as seropositive for CMV; samples with OD ratios $\leq 0.90$ were classified as seronegative for CMV; and samples with OD ratios from 0.91-1.09 were classified as equivocal for CMV.

\subsection{Statistical analysis}

The statistical comparison was done using one-way ANOVA and Student T-test. A P value of $\leq 0.05$ was considered significant.

\section{Results}

Table 1. Cytomegalovirus IgG serostatus of Diyala University male and female students.

\begin{tabular}{|c|c|c|c|c|}
\hline Subjects & No. tested & No. positive & \% seropositivity & Age range (years) \\
\hline Male & 98 & 95 & 96.9 & \\
\hline Female & 88 & 86 & 97.7 & $18-23$ \\
\hline Total & 186 & 181 & 97.4 & \\
\hline
\end{tabular}

Table 2. Cytomegalovirus IgM serostatus of Diyala University male and female students.

\begin{tabular}{cccc} 
Subjects & No. tested & No. positive & \% seropositivity \\
Male & $\mathbf{9 8}$ & $\mathbf{1}$ & $\mathbf{1 . 0 2}$ \\
Female & $\mathbf{8 8}$ & $\mathbf{2}$ & $\mathbf{2 . 3}$ \\
Total & $\mathbf{1 8 6}$ & $\mathbf{3}$ & $\mathbf{3 . 3}$ \\
\hline
\end{tabular}

Table 3. Residency wise distribution of CMV IgG among Diyala University students.

\begin{tabular}{ccc} 
Residency & No. positive & \% seropositivity \\
Urban & $\mathbf{7 2}$ & $\mathbf{4 0}$ \\
Rural & $\mathbf{1 0 9}$ & $\mathbf{6 0}$ \\
Total & $\mathbf{1 8 1}$ & $\mathbf{1 0 0}$ \\
\hline
\end{tabular}

All 186 subjects were apparently healthy male and female students and their age ranged from 18-23 years (Table 1). Out of 186 students, $181(97.4 \%)$ were seropositive for CMV IgG which indicates exposure to CMV. Of those, $95(51.2 \%)$ were male and $86(46.2 \%)$ were female students. The sex wise distribution of CMV IgG seropositive students is given in Table 1. Out of 98 male students, 95 (96.94\%) were CMV IgG seropositive while out of 88 female students, $86(97.73 \%)$ were seropositive. In this age group, the males and females have a similar rate of acquisition of CMV seropositivity.

Regarding CMV IgM, only one male (1.02\%) out of 98 and 2 female $(2.3 \%)$ out of 88 screened students were seropositive (Table 2).

The residency wise distribution of CMV IgG seropositive students is given in Table 3. Residency distribution analysis showed that out of $181 \mathrm{CMV} \mathrm{IgG} \mathrm{seropositive} \mathrm{students,} 72(39.8 \%)$ students were from urban areas and 109 (60.2\%) were from the rural areas of Diyala Province. The results showed that the CMV IgG seropositivity among student lived in rural areas was significantly $(\mathrm{P}<0.0001)$ higher than that among students living in the urban areas.

\section{Discussion}

The principal finding of the present study is that very high percentage of the apparently healthy students was CMV IgG seropositive which means they harbour the virus in their peripheral blood which can be potentially infectious when they donate blood. Our results revealed that $96.9 \%$ of the male and $97.7 \%$ of the female healthy university students were CMV IgG seropositive. Abuharfeil and Megdam [11] conducted a seroepidemiologic study of herpes simplex virus type 2 and cytomegalovirus among young adults in northern Jordan. The authors randomly collected blood samples from 360 male and 390 female healthy university students aged 18-24 years and tested for herpes virus type 2 (HSV-2) and cytomegalovirus (CMV) antibodies. The prevalence of CMV seropositivity was $75.6 \%$ in males and $77.2 \%$ in females as detected by ELISA. Recently, Barah [12] studied the seroepidemiology of immunoglobulin (IgG) for herpes simplex virus types 1 and 2 (HSV 1-2), varicella zoster virus (VZV), and cytomegalovirus (CMV) among university female students of childbearing age in Syria and reported that $238(74.5 \%)$ out of 316 sera were positive, and $25.5 \%$ were negative for CMV specific IgG. The difference in the CMV IgG seropositivity between the results of the present 
study and the studies conducted in Jordan and Syria $[11,12]$ may be related to the differences in socioeconomic and other factors.

The low CMV IgM positivity reported in our study is matching the low rates reported in the studies conducted in Jordan [11], Syria [12], Iran [5], and India [10]. Chaudhari and Bindra [10] conducted a prospective study in which 431 voluntary blood donors were screened for CMV IgG and IgM and found that 379 (87.9 \%) subjects were seropositive for CMV IgG while seven (1.6\%) were CMV IgM positive. Recently, Bagheri et al. [5] collected 240 serum samples from Iranian pregnant women and measured the CMV IgG and IgM markers using ELIZA method and found that the CMV seropositivity rate was $72.1 \%$. Only $6(2.5 \%)$ women were CMV IgM seropositive.

The high CMV seroprevalence among the students living in the rural areas in comparison to those living in the urban areas may be related to the level of hygiene and socioeconomic reasons. Bagheri et al. [5] found a significant correlation between the residence place and the CMV IgG seropositivity rate among Iranian pregnant women. The authors reported that $67.1 \%$ of the participants from the urban areas were CMV IgG seropositive which was significantly lower than that $(82.8 \%)$ reported among those living in the rural areas.

The health authorities at Diyala Province used to organise campaigns for collecting blood from the students of Diyala University who donate generously. Based on the fact that CMV can be transmitted via transfusion of blood or blood components [10], CMV-seronegative recipients are at a risk of primary infection with this virus after receiving blood or blood products from CMV-seropositive donors [13, 14]. On the other hand, CMV-seropositive recipients are also at risk of reinfection by a new strain of this virus when they receive blood products from CMV-seropositive donors [14]. This is very important issue, especially in pregnant women who are CMV-seronegative and even those who are CMV-seropositive when they need blood transfusion during the course of pregnancy.

Despite the low number of participants and the nature of the study (cross-sectional), the results give an indication for the high exposure of the community to the cytomegalovirus and that very high percentage of the students; especially the female students of childbearing age are harbouring the virus in their blood. These young ladies are at risk of reinfection with new strains of CMV if they need blood transfusion for any reason.

\section{References}

[1] Dew, W.L. Herpes viruses. In: Rayan K.L., Ray C.G., editors. Sherris Medical Microbiology. $4^{\text {th }}$ ed. Columbus: McGraw Hill 2004; 555-576.

[2] Munro, S.C., Hall, B. and Whybin, R. (2005). Diagnosis of and screening for cytomegalovirus infection in pregnant women. J. Clin. Microbiol., 43: 4713-8.

[3] Sotoodeh, A., Jamshidi, M. and Farjam, M.R. (2010). Cytomegalovirus immunity in South of Iran. Am. J. Infect. Dis., 6: 8-12.

[4] Yinon, Y., Farine, D., Yudin, M.H., Gagnon, R., Hudon, L. and Basso M. (2010). Cytomegalovirus infection in pregnancy. J. Obstet. Gynaecol. Can., 32: 348-354.

[5] Bagheri, L., Mokhtarian, H., Sarshar, N. And Ghahramani, M. (2012). Seroprevalence of cytomegalovirus infection among pregnant women in Eastern Iran. Braz. Infect. Dis., 16: 402-403.

[6] Nieto, F.J., Sorlie, P., Comstock, G.W., Wu, K., Adam, E., Melnick, J.L. and Szklo, M. (1997). Cytomegalovirus infection, lipoprotein (a), and hypercoagulability: an atherogenic link? Arterioscler Thromb. Vasc. Biol., 17: 1780-1785.

[7] Danesh, J. and Appleby, P. (1998). Persistent infection and vascular disease: a systematic review. Exp. Opin. Invest. Drugs, 7: 691713.

[8] Froberg, M.K., Seacotte, N. and Dahlberg, E. (2001). Cytomegalovirus Seropositivity and Serum Total Cholesterol Levels in Young Patients. Ann. Clin. Lab. Sci., 31: 157-161.

[9] Roback, J.D. (2002). CMV and blood transfusions. Rev. Med. Virol., 12: 211-9.

[10] Chaudhari, C.N. and Bindra, M.S. (2009). Seroprevalence of Cytomegalovirus among voluntary blood donors. Med. J. Armed Forces India, 65: 252-254.

[11] Abuharfeil, N. and Megdam, M.M. (2000). Seroepidemiologic study of herpes simplex virus type 2 and cytomegalovirus among young adults in northern Jordan. New Microbiol., 23: 235-239.

[12] Barah, F. (2012). Prevalence of herpes simplex types 1 and 2, varicella zoster virus, cytomegalovirus, immunoglobulin G antibodies among female university students in Syria. Saudi Med. J., 33: 990-994.

[13] Sia, I.G. and Patel, R. (2000). New Strategies for Prevention and Therapy of Cytomegalovirus Infection and Disease in Solid-Organ Transplant Recipients. Clin. Microbiol. Rev., 13: 83-121.

[14] Diosi, P. and Kazanjian, P. (2003). Transmission or recurrence? A historical dilemma of iatrogenic infections due to cytomegalovirus. J. Hist. Med. Allied Sci., 58: 56-78. 